\title{
VIRTUAL SCORECARD AS A DECISION- MAKING TOOL IN CREATING VIRTUAL ORGANISATION
}

\author{
W. M. Grudzewski \\ Correspondent Member of Polish Science Academy \\ w.grudzewski@orgmasz.pl
}

A. Sankowska

Warsaw University of Technology, Faculty of Production Engineering e-mail:amsankowska@wp.pl

M. Wantuchowicz

Warsaw University of Technology, Faculty of Production Engineering e-mail: monika.wantuchowicz@wp.pl

POLAND

Peter Drucker "If you cannot measure it, you cannot manage it". We want to elaborate the partners for co-operation in Virtual Organisation (VO). Our specific goal is to elaborate the Virtual Scorecard - a measure of organization abilities to form VO, which will give the answer for the following questionHow well is the organization prepared to form VO?

\section{INTRODUCTION}

Today enterprises look for solutions that might secure them from more and more unpredictable changes in business environment and provide stable and successful existence. They search for various methods of decreasing risk and cost and benefiting from fast closing market opportunity. The virtual form of organisation could be one of the solutions that bring better understanding and new approaches to dealing with "ad hoc" cooperation (e.g. proper principles, formal models). The article distinguishes the special needs for measurement tool - Virtual Scorecard (VSc) - that focuses on three domains considered to be essential in effective Virtual Organisation (VO) and provides a large normative data set against which the potential partners for co-operation can be selected. Data derived from Polish IT sector enabled us to conceptualize $\mathrm{VSc}^{1}$.

\section{THE CONCEPTION OF VIRTUAL SCORECARD}

\subsection{Working definition}

The composition of VO depends on requirements of a specific market opportunity and how other orgasniations may satisfy these requirements (Wywrocki, 1999,

\footnotetext{
${ }^{\mathrm{l}}$ For more information and examples of the general partners selection tool interested readers are referred to e.g. "collaboration maturity audit" ("Cambridge Manufacturing Review", 2002).
} 
Lipnack and Stamps, 1997). VO is temporary, ad hoc network of independent enterprises linked up by ICT and working together to exploit market opportunity.

\subsection{Process of potential partners selection in VO model}

In the cycle of forming VO we use a model (Saabeel et al., 2002) that consists of three layers (see Figure 1), including: the universe of modules, the Dynamic Network (DN) and VO. According to this concept organizations forming the VO are a part of a larger network within which a selection is made ${ }^{2}$.

Firstly, potential members are selected from the universe of modules - that is the set of all organizations that represent different objectives, strategies, competencies and resources and thereby different capabilities to act in the network. The ability to select potential partners from the universe of modules is essential for $\mathrm{DN}^{3}$. It allows to reduce complexity, interdependence and uncertainty. So far uncertainty of strangers is so huge, that decision-makers prefer to stay with already known partners form former collaboration (stable DN). Owning to that great number of new potential successful partnerships establishment will never occur ${ }^{4}$.Therefore, providing a tool for selecting strangers to set of DN could enhance already existing connections in DN.

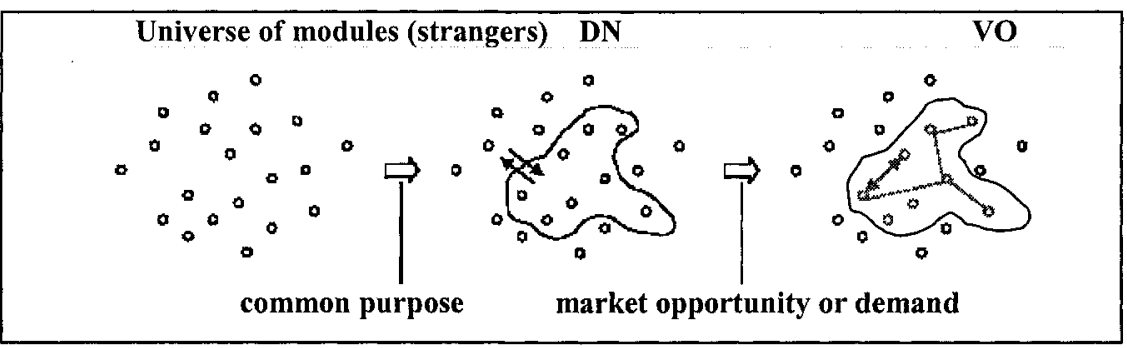

Figure 1 - Three layers in the process of partners' selection for VO (compare with Saabeel et al., 2002)

The pre-selection mechanism has to ensure that the $\mathrm{DN}$ members can work in VO by evaluating their capabilities to cooperate in form of VO. The crucial issue is the clearness of the assignment criteria. We obviously need to deliver to decisionmakers final scores of strangers' crucial holistic collaborative competencies in order to make comparisons between strangers and more effective decisions.

\subsection{Virtual-Scorecard in process of potential VO's partmers selection}

We define a Virtual Scorecard ${ }^{5}$ as a measuring instrument of organizations'

\footnotetext{
2 Many authors argue that there is a number of strategic effects of collaboration and co-operation (Dyer, 1996; Hamel et al., 1989). This model presumes that organizations are motivated to form VO at particular moment, when the market opportunity or demand occurs.

3 The Dynamic Network is defined as an open-ended collection of pre-qualified organizations that are able to form VO in order to benefit from specific market opportunity.

${ }^{4}$ Notice that the map of Internet traffic looks similar to the maps of maritime and land transport.

${ }^{5}$ Virtual because it concerns the potential cooperation in reality in VO when there are suitable conditions and a lucrative market opportunity. Scorecard because it measures condition of the enterprise to collaboration.
} 
capabilities used when organization want to participate in potential VO. It will allow the decision maker to find an open-ended collection of pre-qualified partners that have met defined criteria (Grudzewski and Hejduk, 2000). That means they are adopted to co-operate in future $\mathrm{VO}$ and agree to form a pool of potential partners in VO.

Our first step was defining the most important criteria verifying whether an organization is ready to work in the networks of organizations. To make the decision process more efficient we selected a subset from a wider set of criteria. Then, we found the most fit criteria which should be taken into consideration in the decisionmaking process. The selection of criteria from the "universe of criteria" was based on the results of survey conducted in IT companies that have got experience in temporary co-operation. There was an assumption that common proposal would be established.

VSc as a decision-making tool in the process of VO management allows to:

a. Make the process of partners' selecting more formalized and more efficient;

b. Create the DN database with potential partners for VO that have met specific criteria;

c. Make the process of selecting, pre-qualifying partners to VO clearer (the process of transition to the second layer - see Figure 1);

d. Make response to market opportunities more rapid (the choice from prequalified members is easier and faster than from the whole universe of modules);

e. Reduce the complexity and the uncertainty in the pre-selection process of business partners - standardized previously - which are from the universe of modules (risk management).

\section{THE SURVEY}

\subsection{Objectives of the survey}

There were two main phases in our survey:

a. Selecting the most important factors from the initial list, called testing factors, based on conducted survey. The thesis in this survey was as follows: selected factors, which would gain the highest ranks, were crucial for the success of VO. In this phase there was compiled a suitable questionnaire. It was completed in Polish IT companies by workers on managerial and non-managerial positions. These workers assessed the rank (the importance) of 48 factors which were considered while deciding in favour of initial list of partners for cooperation. A result of that phase was the final set of testing factors;

b. Creating VSc that is the tool veryfing if a certain enterprise is a suitable potential cooperant. The assessment and verification is based on fulfilling the conditions from the list of crucial factors. VSc can be also seen as a set of guidelines for developing these organizations which aspire to take part in relations based on the networks.

\subsection{Methodology in the empirical study}

The utilization of experts' opinions in a real world context has value (Bunn, Wright, 
$1991)^{6}$. This paper reports on a survey of 11 judges (experts) that are from ITservices companies in Poland (Warsaw) and are experienced in temporary "ad hoc" cooperation. This group represents a cross-section of staff working in VO in IT sector. All responses are made on an anonymous basis. The judges were asked to rank the importance of 48 initial factors which allow to evaluate the organizations' ability to become a potential partner in VO if there is a common purpose.

To face with the importance of factors we use a sum of ranks that each $j$ factor receives according to the following formula from all experts:

$$
R_{j}=\sum_{i=1}^{p} R_{i}
$$

This way we identify which particular factors are the most important ones (those with the highest sum of ranks). In our study the maximum sum of ranks is 44 . We pick up those factors that receive at least $80 \%$ of maximum sum that is 35 .

The experts' answers analysis is based on the analysis of concordance of each opinion. The team is authoritative if the experts are at least moderately consistent in their opinions. We have got $p=11$ of experts and $n=48$ of factors which are ranked according to the scale with $k$ degrees $(k=5)$. The starting point for the experts opinions analysis is the overall table with the survey results where $R_{i j}$ means rank with $m$ number $(m=0, l, \ldots, k)$ assigned to $j$ factor by $i$ expert $(i=l, \ldots, p)$.

The analysis of the survey outcomes allows to:

a. Assess the concordance of experts' replies for each factor separately and for all factors in total;

b. Define the common opinion in the group of experts.

Regarding the analysis of the survey outcomes above the coefficient of dispersion was used. This coefficient measures the degree of agreement among judges within $j$ factor. Formula shows the computation of this coefficient for $j$ factor, represented as $h_{j}$ :

$$
h_{j}=\frac{k}{k-1}\left(1-\sum_{m=0}^{k} f_{j m}^{2}\right)
$$

where:

$k$ - the number of ranks for each factor $(k=$ const $=5)$;

$f_{j m}$ - frequency of occurrence of $m$ rank in $j$ factor.

We used the Kendall Coefficient of Concordance $W$ (Siegel, Castellan, 1988), to determine the overall agreement among $p$ judges who were assessing the importance of a given set of $n$ factors which were taken into consideration in the process of selecting members of DN. Kendall's $W$ is obtained from the following formulas:

$$
W=\frac{12 S}{p^{2}\left(n^{3}-n\right)} \quad S=\sum_{j=1}^{n}\left(\sum_{i=1}^{p} R_{i j}-\bar{R}\right)^{2}
$$

\footnotetext{
${ }^{6}$ There is a large literature analyzing whether the predictions and assessments obtained from judges are more accurate than these from other statistical methods provided that the researchers obtain independent opinions from between 5 and 20 experts (Armstrong ed., 2002).
} 


$$
\bar{R}=\frac{\sum_{j=1}^{n} \sum_{i=1}^{p} R i j}{n}
$$

where:

$p$ - the number of judges (respondents in the survey);

$n$ - the number of factors $(n=1, \ldots 48)$

$\bar{R}$ - average value of the ranks for all factors

$R_{i j}$ - the rank of $j$ factor $(j=1, \ldots, 48)$ of the analyzed feature measured with ordinal scale assessed by $i$ judge $(I=1, \ldots, p)$.

To assess the significance of $W(0 \leq W \leq 1)$ we use $\chi^{2}$ statistics (chi-squared test) according to the following formula:

with $(n-1)$ degrees of freedom.

$$
\chi^{2}=p(p-1) W
$$

This allows us to test the statistical significance of $W$. The null hypothesis $\left(H_{o}\right)$ was that the judges who produced rankings were independent from each other. In other words, $H_{o}$ was that the $p=11$ judges were not concordant with each other.

\subsection{Results of the empirical study}

After summing up the ranks for each factor from initial list of 48 factors we found 14 factors that achieved at least sum of 35 . The coefficient of dispersion for 13 factors was from 0,58 to 0,79 . One achieved more than 0,80 so we made a decision to remove it from our list of 14 the most important factors. Results for those 13 significant factors (testing factors) are presented in Table 1.

\begin{tabular}{|c|c|c|c|}
\hline No. & Factor: & $\begin{array}{l}\text { Sum of } \\
\text { ranks }\end{array}$ & $\begin{array}{c}\text { Coefficient } \\
\text { of } \\
\text { dispersion }\end{array}$ \\
\hline 1. & 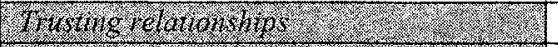 & 40 & 0,58 \\
\hline 2. & 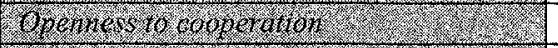 & 39 & 0,64 \\
\hline 3. & 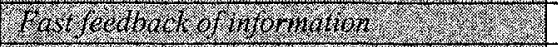 & 39 & 0,62 \\
\hline 4. & 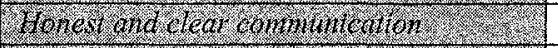 & 39 & 0,64 \\
\hline 5. & 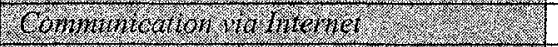 & 38 & 0,70 \\
\hline 6. & 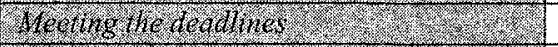 & 38 & 0,70 \\
\hline 7. & 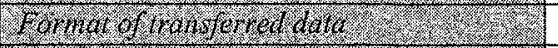 & 37 & 0,79 \\
\hline 8. & 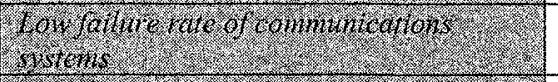 & 37 & 0,72 \\
\hline 9. & 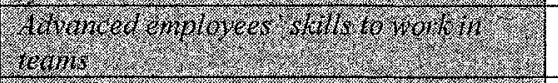 & 37 & 0,70 \\
\hline 10. & 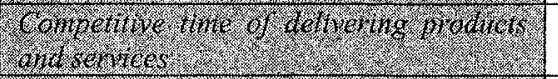 & 37 & 0,56 \\
\hline 11. & 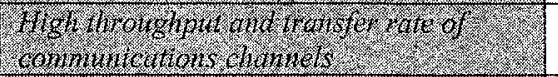 & 36 & 0,70 \\
\hline 12. & 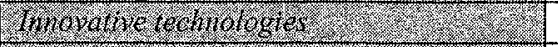 & 36 & 0,79 \\
\hline 13. & 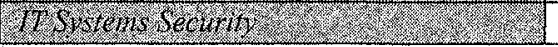 & 35 & 0,79 \\
\hline
\end{tabular}

Table 1 - Testing factors 
As we see above the highest ranked factors are trust and openness to cooperation. Those two factors and fast feedback of information, honest and clear communication as well as working in teams are concerning the soft abilities. They embrace competences connected with high corporate culture and ethics. The other factors like: Internet, formats of data, low failure rate of communications systems, throughput and transfer rate of communications channels as well as security of IT unambiguously are embedded in technical facets of VO. Consequently, the rest of factors, that is meeting the deadlines, time of delivering services and products as well as innovative technologies, are rather connected with core competencies in the specific area of activity. The findings of our empirical study in IT sector clustered around three core domains important for VO.

As far as concordance of experts' opinion for these 13 factors is concerned we have:

$$
\begin{array}{cc}
c & W=0,7 \\
1-\alpha=0,05 & n^{\prime}-1=12 \\
\chi^{2}=75 & \chi_{(1-\alpha ; n-1)}^{2}=21 \\
\chi^{2}>\chi_{(1-\alpha ; n-1)}^{2}, & \text { so we reject } H_{o}
\end{array}
$$

Concluding - judges do agree on the factors and the results are not random in statistical sense. The team of judges is competent and helps to create VSc.

\section{VIRTUAL SCORECARD FORMULATION}

We had divided 13 important factors (testing factors) into three main domains: technical, cross-culture and core competence.

Virtual Scorecard is illustrated in Table 2.

In VSc should be determined weights for each factor in order to get the final assessment. This evaluation can help in deciding if an organization is capable of working in VO and to create the DN database.

We want to emphasize that it is initial outlook of VSc. Further survey should be carried on in order to find the correlation among all factors. Following the rule of diagnostic (testing) factors the ones that are strongly correlated should be removed and only their representative will appear in the final VSc. Moreover, VSc could be developed by finding quantitative/qualitative metrics (Parth, Gumz, 2003) for its factors. Due to the complexity of single factors, it can be necessary to define them through more than one performance measure, it order to characterize them sufficiently. These are the goals for the next research.

Thus, we are looking for score board that the multiplication of few very important not correlated weighted factors that each of them has got quantitative or/and qualitative measures. The less factor we have, the less time and money we spend on getting information about their values in potential partners. 
Table 2 - Virtual Scorecard - How well are the partners prepared to form VO?

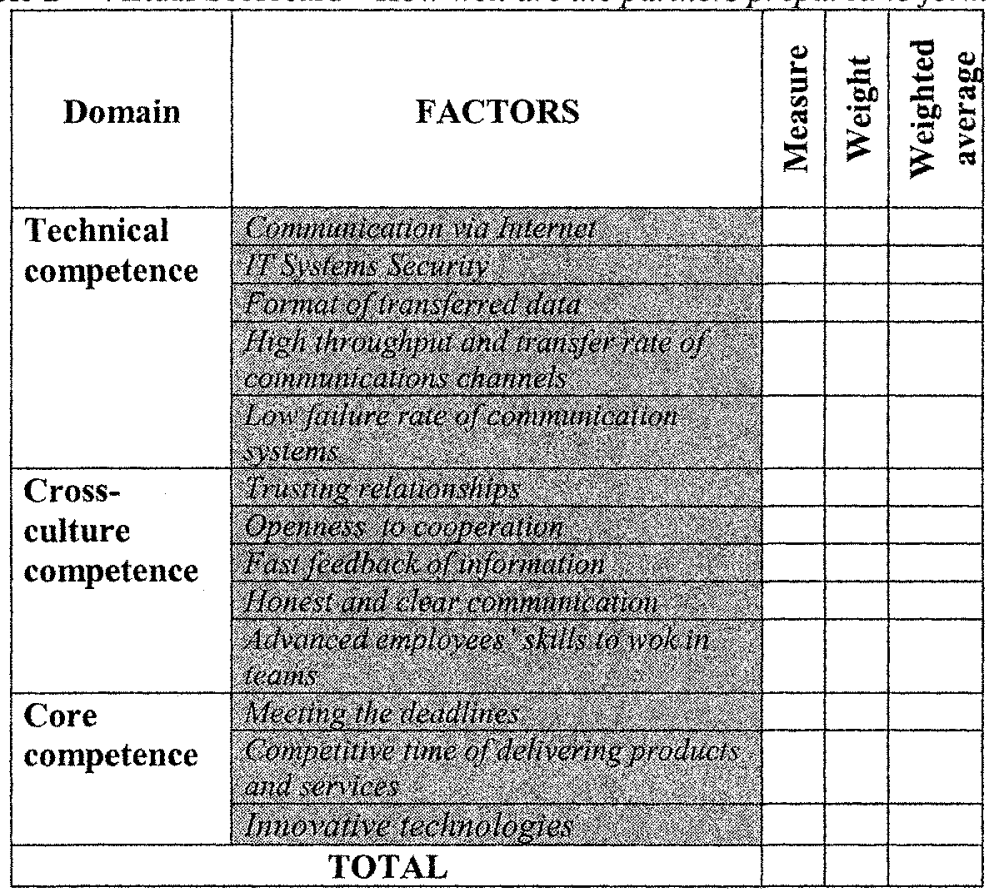

\section{CONCLUSIONS AND SUGGESTIONS FOR FUTURE RESEARCH}

The VSc is a clear, concise user-friendly and provides a useful information to select the potential partners for co-operation in VO. Our another research should improve and build up already existing VSc. We want to eliminate those factors that are correlated with each other. It would protect from repeating similar information.

Survey that led us to the formulation of VSc allows us to make some conclusions. After survey we acknowledged the great importance of trust and openness to collaboration for effective cooperation in VO. Furthermore, results provide a context for improvements in organization within its ability to participate in VO. Overall the general trust of the VSc has been well received by over ten experts from IT sector in Poland and they have acknowledged the importance of cooperants' selecting.

The problem is to find appropriate metrics for the selected factor as well as to find mechanism for their development. We can presume that in the area of the most important factors further studies must be undertaken to increase consciousness of these factors. Future research can consist of obtaining measures and methods of enhancing each factor with stress especially put on confidence factor. 


\section{REFERENCES}

1. Bunn $\mathrm{D}$, Wright $\mathrm{G}$. Interaction of judgmental and statistical forecasting methods: issues and analysis. "Management Science", 37, 1991.

2. Dyer J. Specialized supplier networks as a source of competitive advantage: evidence from the auto industry. "Strategic Management Journal", vol. 17, no. 4, 1996.

3. Collaborate to innovate. "Cambridge Manufacturing Review", Summer, 2002, http://www.ifm.eng.cam.ac.uk/service/cmr.

4. Grudzewski WM, Hejduk I. Przedsiębiorstwo wirtualne (The Virtual Enterprise). Difin, Warsaw, 2002.

5. Hamel G, Doz YL, Prahalad CK. Collaborate with your competitors - and win. "Harvard Business Review", January-February, 1989.

6. Lipnack J, Stamps J. Virtual Teams: Reaching across Space, Time and Organisations with Technology. John Wiley and Sons, united Kingdom, 1997.

7. Makridakis S, Wheelwright SC. Forecasting - methods and applications. John Wiley and Sons, New York, 1998.

8. Parth FR, Gumz J. How Project Metrics Can Keep You from Flying Blind. www.ProjectAuditors.com, Project Management Institute, 2003.

9. Principles of forecasting, JS. Armstrong (ed.). Kluwer Academic Publishers, Massachusetts, 2002.

10. Przedsiębiorstwo przyszłości (The Enterprise of the future), WM. Grudzewski, I. Hejduk (ed.). Difin, Warsaw, 2000.

11. Saabeel W, Verduijn TM, Hagdorn L, Kumar K. A model of virtual organisation: a structrure and process perspective. "Electronic Journal of Organizational Virtuainess", vol. 4, no. 1, 2002.

12. Siegel S, Castellan JN. Nonparametric Statistic for the Behavioral Sciences. Second Edition, McGraw - Hill Book Company, New York, 1988.

13. Wywrocki A. Communication supported by Internet Technology between business parters in Virtual Organisations. Linköping University, 1999. 